\title{
Building a donor base for college and university libraries \\ Exploiting archives as a foundation for development
}

I:

today's economic environment, there

are pressures to fundraise throughout all of the academic units at colleges and universities, including libraries. Unfortunately, however, there is no natural constituency for the academic library. While the library may have been instrumental in their successful academic career, alumni more often than not, feel no loyalty to it, as they might to their department, school, college, or even sports team. The school library, which may have served as the important $\operatorname{cog}$ in their academic success, is taken for granted in its apparent supporting role.

Until recently, solidifying a donor base was of little consequence to the academic library; college and university libraries got by with minimal fundraising, often assisted by friends groups that provide financial support via annual membership fees and occasional fundraising events. College and university libraries friends groups are frequently made up of current and retired faculty and librarians, who understand the important role of the campus library. The trick for academic libraries in the current economy is to bring in new life and new blood in support of the library.

A key to this concept is to connect the interests of potential donors with the goals and objectives of the library. Current and retired faculty and library staff understand the importance of the library and its mis- sion; but how can the library communicate its mission in a way that attracts alumni and other community supporters?

In recent years, library administrators, aware of the unique materials housed in their special collections departments and university archives, have begun to work with the library's development officers to showcase and exploit these items, the crown jewels of not only the library, but the university. However, while the sometimes esoteric materials in special collections may be rare and exceptional, if alumni or other library patrons have no interest, passion, or connection to the materials, then there is no draw or appeal for university library fundraising activities. But one subject area that is of immense interest to the alumni and the university community are the materials housed in the university archives. The mission of the university archives varies from school to school, but in most instances it serves to document and preserve the history of the institution itself.

Recent research indicates that the promotion and marketing of history and tradition at colleges and universities is an easy way for university libraries development personnel to engage with alumni.

Eddie Woodward is FSU Heritage Protocol archivist at Florida State University, e-mail:eddiebud1@yahoo.com ○ 2013 Eddie Woodward 
An article by David Cheng determined that "rituals and traditions related to institutional history and heritage play a powerful role in shaping students' sense of campus community," and of the many variables in Cheng's research, the student's pride in the "institution's history and heritage" ranked highest. ${ }^{1}$

Citing the "Alumni Attitude Study," conducted by the Performance Enhancement Group, Ltd. for the Arkansas Alumni Association in 2009, Anthony Dean McAdoo's dissertation concluded that: "History and tradition was the single most powerful factor which can impact overall current opinion of the University of Arkansas. Additional factors having a significant relationship in combination with history and tradition included success of athletic teams, campus aesthetics and accomplishments of alumni."

These same findings, regarding "history and tradition" were confirmed in the Performance Enhancement Group, Ltd.'s "Alumni Attitude Study," conducted for the Florida State University Alumni Association in 2011. Higher education historian, John R. Thelin summarized the benefits of promoting the history and heritage of an institution to alumni with a bottom-line assessment: Colleges and universities that

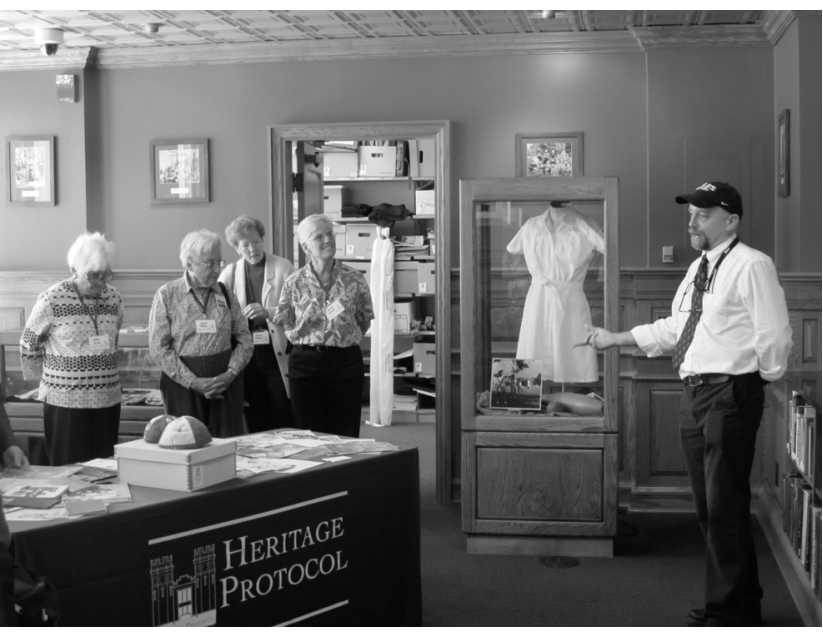

Memorabilia from the Dr. Mary Lou Norwood Reading Room. alumni community, and through the library's association with these heritage preservation efforts, build a donor constituency. University libraries should find ways to market and promote the archives to alumni through historic exhibits, both in house and online, and through other events and initiatives. In this way, not only the archives, but the university libraries are perceived by the alumni as the entities responsible for documenting and preserving the history of the institution.

\section{Heritage Protocol at FSU}

This is the case at Florida State University (FSU), where for the past few years the library's administration and development archives in promoting its mission to docuofficer have teamed up with the university failed to recognize or promote their history and heritage, "lagged in endowments and fund-raising." 3

With the university archives serving as the traditional home for the school's institutional memory, and with an understanding of alumni support for documenting and preserving the school's history and heritage, college and university library administrators and their development/advancement team should seek out ways to exploit their connection or stewardship of the school's archives. This relationship gives them the opportunity to make inroads within the 
colleges. Generally, these events involve partnering with the FSU Alumni Association and/or the FSU Foundation.

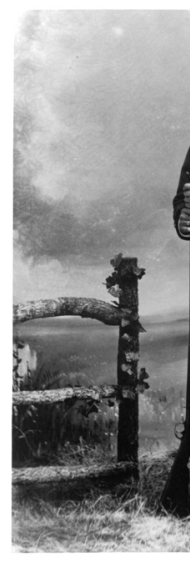

The Heritage Protocol archivist has traveled from San Francisco to Jacksonville, from Atlanta to Tampa representing the ar-

chives and the University Libraries at these types of functions. Off-campus events are usually orchestrated with heavy FSU Foundation involvement and a sometimes odd assortment of departments, schools, and colleges (dependent on the distance from campus and the donor prospects in the area). With all of these events, it is a win-win situation. The other campus stakeholders (usually the FSU Foundation) take the lead in organizing the event, and participation at the gathering raises awareness of both University Libraries and Heritage Protocol.

Additionally, Heritage Protocol has worked with University Libraries on a number of special initiatives that solidify the libraries relationship, and, more importantly, its support for university preservation efforts. The first of these initiatives involved the creation of a space in the library devoted to using the resources of the collection, and promoting the history of the university.

A former photocopy area in the library, today known as the Dr. Mary Lou Norwood
Reading Room, was renovated through the donations of Heritage Protocol supporters. It opened to great fanfare, with a formal dedication ceremony by the president of the university, during our Heritage Day celebrations in 2009.

Local and campus news coverage brought publicity to the library and the archive, which was another win-win. The room is more formal in comparison to the rest of the library and can be used for some high-end events, but for the most part it is used by students as a study area. There are four display cases, numerous historic photographs on the walls, and a run of yearbooks and other FSUrelated publications for browsing. The display cases feature different themes or eras from FSU's his-

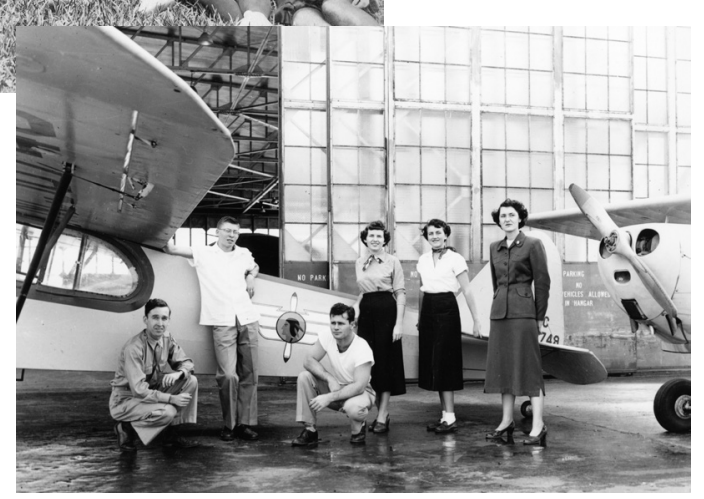

Photographs from the FSU history exhibit (left to right):1880s-West Florida Seminary Cadet, 1916Florida State College for Women Basketball Team, and 1940s-FSU Flying Club.

tory and are routinely swapped out. Alumni sometimes seek out the room when they are on campus, and some campus tours and orientation sessions visit the room where the archivist might give brief talks on FSU history. It is hoped that the room will help the current student population learn a little more about the history of the school, and that they will leave the university with an understanding of the role that the library plays in preserving that history. 
Another more recent Heritage ProtocolUniversity Libraries collaboration involved the publishing of a book on FSU history, Florida State University, in 2012. ${ }^{4}$ The book was authored by the Heritage Protocol archivist with the support of the dean of University Libraries, and all of the royalties from the sale of the book in bookstores and online goes to the University Libraries General Fund.

In addition, through an agreement with the publisher, FSU is permitted to purchase the book at wholesale cost so that it can be used as a fundraising tool for the library. Currently, the book is offered as a "gift" in exchange for donations of $\$ 35$ or more (yielding substantially more for the library than the author's royalties).

As there are few books devoted to the history of FSU, the title should continue to provide publicity and a steady, albeit small, stream of income to the library for some time into the future. In addition to the publicity surrounding the publication of the book, University Libraries hosted a successful book launch at the library, which was attended by more than 100 alumni and others. Again, the entire book project serves to solidify the relationship between the library and the archive, publicizing the book, the library, and Heritage Protocol.

Held in conjunction with the book launch was a library-hosted exhibit on the history of FSU in the 1950s, 1960s, and 1970s-prime donor prospect eras. This FSU history exhibit was one of the more elaborate (and costly) shows in the short history of the library's exhibit room. Posters, photographs, and text labels were all professionally mounted to create a cache of reusable FSU history-related exhibition materials.

The effort, time, and expense proved worthwhile, as the reviews received on the display were outstanding. The exhibit was publicized on both the library and Heritage Protocol Web site, and in the campus and local newspapers. In addition, word of mouth appears to have played a major factor in marketing the exhibit among alumni and faculty.
After its installation, alumni routinely visited, which was no small feat considering the challenges involved in parking on FSU's campus. And frequently, planned visitors arranged to meet with the archivist and/or Special Collections staff for more informative tours. Most impressive, however, was the response from current student population. With its easy accessibility on the library's main floor, students regularly visited the exhibit room and filled the guestbook with an unprecedented number of favorable comments. This overall positive response was responsible for extending the exhibit for a longer period than had previously been scheduled. The display of FSU history in the University Libraries exhibit area, again, reinforced the notion of the University Libraries role as stewards of the school's tradition, history, and heritage.

With each of these initiatives, the library's donor prospects increased, as did the marketing and positive public relations of the library. Heritage Protocol in its supporting role as an outreach tool elevates the library's engagement with students, alumni, and other potential supporters, while reinforcing the role of the library and archives in preserving the university's heritage.

\section{Notes}

1. David X. Cheng, "Students' Sense of Campus Community: What it Means, and What to do About It," NASPA Journal 41, no. 2 (Winter 2004), 222, 229.

2. Anthony Dean McAdoo, "Factors Affecting the Institutional Perception of Alumni of the University of Arkansas" (Ph.D. dissertation, University of Arkansas, 2010), 90; Performance Enhancement Group, Ltd., "Alumni Attitude Study" (presented, Florida State University Alumni Association, Tallahassee, Florida, 2011).

3. John R. Thelin, "Archives and the Cure for Institutional Amnesia: College and University Saga as Part of the Campus Memory," Journal of Archival Organization 7 (2009), 7.

4. Eddie Woodward, Florida State University (Arcadia Publishing, 2012). n 